\title{
Modelowanie taboru bimodalnego z wykorzystaniem istniejących skrajni kolejowych
}

\begin{abstract}
W artykule przedstawiono analizę możliwości powiększenia przestrzeni ładunkowej zestawu bimodalnego przy zachowaniu obowiqzujacej skrajni kolejowej zgodnej z kodeksem UIC 505-1.
\end{abstract}

\section{Wstęp}

Rozwój transportu intermodalnego a w szczególności bimodalnego uwarunkowany jest możliwościami poruszania się po określonych szlakach kolejowych. Sytuacją optymalną byłoby aby tabor bimodalny poruszał się po szlakach na których obowiązuje skrajnia określona Kartą UIC 505-1.

Tabor bimodalny należy do najbardziej zaawansowanych technologicznie zestawów transportowych, który posiada następujące zalety [1]:

- najmniejsza masa martwa,

- najkorzystniejsza skrajnia kolejowa [10],

- prostota terminali przeładunkowych.

Obecnie tabor bimodalny jest wykorzystywany do przewozu towarów między określonymi spedytorami. Działa na zasadzie „wahadła”, ewentualnie należy wytypować kilka szlaków na których będzie poruszał się pociąg. Ponieważ w systemie operatorów bimodalnych może znaleźć się operator z dowolnego miejsca w kraju wykorzystani istniejącej infrastruktury kolejowej wydaje się być zasadny. Europejska Umowa o ważniejszych międzynarodowych liniach transportu kombinowanego i obiektach towarzyszących (skrót „AGTC”), wyznacza korytarze na których moga poruszać się pojazdy intermodalne i $\mathrm{w}$ tym celu zaleca modernizację szlaków prowadzić w ten sposób, że będą one przystosowane dla pojazdów mieszczących się w skrajni GB [3]. Na pozostałych szlakach obowiązywać będzie skrajnia wg UIC 505-1 [2].

W świetle powyższych informacji, w celu upowszechnienia transportu bimodalnego, należy połączyć ze sobą dwa elementy:

1. wykorzystując zaletę „najkorzystniejszej skrajni kolejowej" dostosować gabaryty naczepy siodłowej używania do skrajni wg UIC505-1,

2. wykorzystując nowoczesne systemy obróbki, pomiarów oraz pewnych założeń eksploatacyjnych i wykorzystania możliwości które dają przepisy zbudować zupełnie nową jednostkę ładunkowa.
Takie nowoczesne podejście spotykamy już w przypadku obliczania skrajni dla wagonów kolejowych [9].

Niniejszy artykuł jest częścią większego opracowania dotyczącego taboru bimodalnego. Ma on na celu wskazanie istotnych zmiennych w zależnościach analitycznych do obliczania skrajni taboru bimodalnego, które pozwalają na powiększenie wymiarów naczepy w porównaniu $\mathrm{z}$,tradycyjnymi” metodami obliczeń. Określenie „Metoda tradycyjna” nie jest określeniem precyzyjnym i nie znajduje pokrycia $\mathrm{w}$ przepisach krajowych i międzynarodowych oraz w literaturze, należy więc dodatkowo sprecyzować używane pojęcie. Metodą ,tradycyjną" nazwano obliczenia skrajni wg Kodeksu UIC 505-1, które zastosowano przy obliczaniu skrajni dla pociągów bimodalnych $[4,5,6,7,8]$.

\section{Możliwości powiększenia przestrzeni ladunko- wej}

Dotychczasowo obliczenia opierano na kodeksie UIC 505-1 [2]. Podstawą obliczeń jest istnienie zarysu odniesienia. Zarys odniesienia ulega zwężeniu, a jego zwężenie jest zależne od wielkości charakterystycznych rozpatrywanego pojazdu. Typowe zwężenia skrajni pokazano na rys. 1.

Na rysunku 1 pokazano przekrój poziomy zarysu skrajni dla wagonu kolejowego oraz dla naczepy bimodalnej. Jak można zauważyć dla tradycyjnego wagonu towarowego istotne są zwężenia wewnętrzne i zewnętrzne. Dodatkową przeszkodą przy projektowaniu jest konieczność uwzględnienia przewężenia na końcach pociagu. Dla przewozów bimodalnych nie istnieje konieczność dokonywania obliczeń dla zwężeń zewnętrznych w części górnej, gdyż cała naczepa znajduje się między czopami skrętu wózków. Dla pojazdu bimodalnego należy sprawdzić tylko zwężenia zewnętrzne w obrębie części dolnych (wózka).

Zwężenia wewnętrzne Ei oraz zewnętrzne Ea określa się po uwzględnieniu następujących podstawowych zależności [2]: 

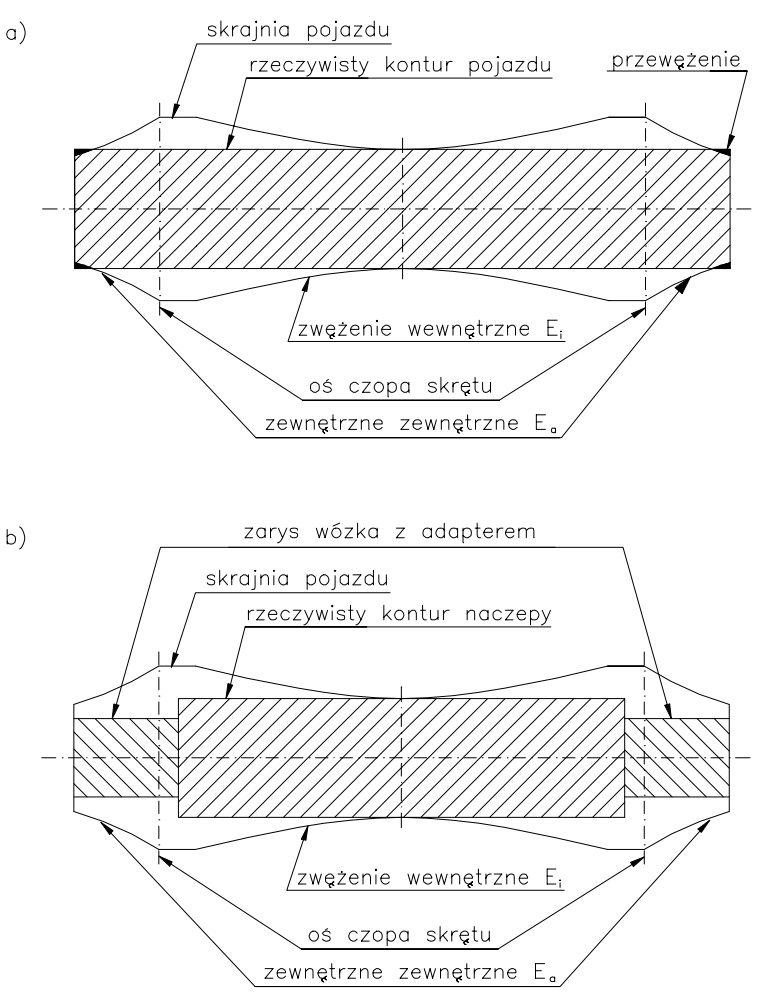

Rys. 1. Zwężenia zarysu skrajni: a) dla tradycyjnego wagonu, b) dla systemu bimodalnego

$E_{i}=\frac{a n_{i}-n_{i}^{2}+\frac{p^{2}}{4}(A)}{2 R}+\frac{1,465-d}{2}(A)+q(A)+w(A)+z+x_{i}-S_{0}$

$E_{a}=\frac{a n_{a}-n_{a}^{2}+\frac{p^{2}}{4}(A)}{2 R}+\frac{1,465-d}{2}(A)+q(A)+w(A)+z+x_{a}-S_{0}$

gdzie:

A -współczynnik zwężenia oznaczajacy położenie zestawów kołowych w torze,

a-rozstaw czopów skrętu wózków,

$n$-położenie przekroju,

$p$ - rozstaw osi wózka,

$R$ - promień tuku,

$d$-maksymalne zużycie zestawu kołowego,

q-luzy poprzeczne,

w-luz w czopach skrętu,

$z$ - przesunięcie quasistatyczne,

$x_{i}, x_{a}-$ człony specjalne,

$S_{0}-$ wysięg dodatkowy.

Szukając optymalnych wymiarów naczepy należy przeanalizować poszczególne człony zależności 1 i 2 , a następnie ocenić możliwości precyzyjniejszego określenia wartości parametrów. Należy również zastanowić się nad możliwościami dokonania kryteriów zmian które pozwolą na powiększenie przestrzeni ładunkowej.

Poniżej zaprezentowano szczegółową analizę zależności 1, która ma zastosowanie dla systemu bimodalnego. Jak widać $\mathrm{z}$ rysunku 1, dla systemu bimodalnego istotne są zwężenia między czopami skrętu, a nie jak dla tradycyjnego wagonu gdzie istotne są zwęże- nia między czopami skrętu, ale równie ważne są zwężenia zewnętrzne.

\subsection{Człon dotyczący położenia pojazdu w luku toru (wysięg geometryczny)}

Człon zależności 1 opisujący geometryczny wysięg rozpatrywanego przekroju poprzecznego w stronę wewnętrzną łuku toru o promieniu $\mathrm{R}$ :

$$
\frac{1}{2 \mathrm{R}}\left(\mathrm{an}_{\mathrm{i}}-\mathrm{n}_{\mathrm{i}}^{2}+\frac{\mathrm{p}^{2}}{4}\right)
$$

W członie tym zmiennymi, które należy podać analizie są:

- promień łuku R przyjmować można $250 \mathrm{~m}$, a nie jak przewidują niektóre źródła [13] $75 \mathrm{~m}$. Podyktowane jest to tym iż minimalnym łukiem na szlaku kolejowym jest tuk $250 \mathrm{~m}$ natomiast łuk $75 \mathrm{~m}$ jest łukiem mogącym występować $\mathrm{w}$ miejscach takich jak bocznice, zakłady naprawcze itp.

- wartość a - rozstaw czopów skrętu wózków, wynika z przyjęcia typowych wartość długości naczep. Należy przeanalizować wykorzystanie przestrzeni ładunkowej przez założona jednostkę opakowania - np. europaletę.

- wartość n - położenie przekroju jest wartością niezależną i nie będzie poddawany analizie. Jedynie gęstość wykonywania przekrojów może pomóc w stworzeniu „bryły skrajni”

- wartość p - rozstaw osi wózka (baza wózka) analizowana może zostać pod kątem dokładności wykonania, założonych tolerancji, zużycia. Zmiana tej wartości nie będzie analizowana $\mathrm{z}$ uwagi na wykorzystanie typowego wózka Y25.

\subsection{Czlony zależności dotyczące luzów poprzecz- nych}

Luzy poprzeczne mierzy się bezpośrednio na zestawach kołowych lub czopach skrętowych, zakłada się przy tym wszystkie części wykazują największe zużycie. W pracy [13] wykazano, że wystąpienie niektórych zakładanych zużyć jest małe. Analiza zmiennych zostanie przeprowadzona w oparciu o rzeczywiste parametry.

Człon określający luzy poprzeczne zestawu bimodalnego:

$$
\frac{1,465-\mathrm{d}}{2}
$$

Luz zestawu kołowego w torze gdzie wymiar d jest maksymalnym zużyciem zestawu kołowego, jest przyjmowany jako 1410 . Ustalenie tego wymiaru ma bardzo długą historię, a praktyka pokazuje, że jest on zawyżony. 
Kolejnym parametrem wpływającym na luzy poprzeczne jest q czyli luz między zestawami kołowymi i ramą wózka względnie między zestawami kołowymi i podwoziem. W przypadku analizowanego pojazdu bimodalnego jest to luz między zestawami kołowymi i ramą wózka. Jest to przesunięcie poprzeczne pomiędzy korpusami maźnic i czopami łożysk. Dokonać należy rozważań nad możliwościami zacieśnienia tolerancji oraz możliwego zużycia elementów współpracujących.

Ostatnim parametrem mającym wpływ na luzy poprzeczne jest $\mathrm{w}-$ luz $\mathrm{w}$ czopach skrętu. Jest to możliwe przesunięcie poprzeczne czopów skrętowych lub belek bujakowych z położenia środkowego na każda stronę względnie $\mathrm{w}$ pojazdach bez czopów skrętowych możliwe przesunięcie poprzeczne podwozia wobec ramy wózka wychodząc $\mathrm{z}$ położenia środkowego, każdorazowo w zależności od promienia łuku toru i kierunku przesunięcia. W przypadku pojazdu bimodalnego wartość tą ograniczają luzy w elementach mocujących naczepę do adaptera.

\subsection{Człon dotyczący pochylenia pojazdu na usprę- żynowaniu i jego niesymetrii}

Przesunięcie quasistatyczne $\mathrm{z}$ względem środkowego położenia w torze można zapisać wzorem

$$
z=\left[\frac{s}{30}+\operatorname{tg}\left[\eta_{0}-1^{\circ}\right]_{>0}\right]\left|h-h_{c}\right|+\left[\frac{s}{10}\left|h-h_{c}\right|-0,04[h-0,5]_{0}\right]_{>0}
$$

Poszczególne elementy wzoru określają:

- $\frac{s}{30}\left|h-h_{c}\right|$ - część zależności wynikająca z pochylenia na zawieszeniu (przesunięcie poprzeczne na skutek podatności usprężynowania pod działaniem nadmiaru przechyłki lub niedostateczności przachyłki 0,05 m),

- $\operatorname{tg}\left[\eta_{0}-1^{\circ}\right]_{>0}\left|\mathrm{~h}-\mathrm{h}_{\mathrm{c}}\right|-$ część dotycząca niesymetrii (przesunięcie poprzeczne na skutek części niesymetrii, która przekracza $1^{0}$ ),

- $\left[\frac{\mathrm{s}}{10}\left|\mathrm{~h}-\mathrm{h}_{\mathrm{c}}\right|-0,04[\mathrm{~h}-0,5]_{>0}\right]_{>0}$ - część, która uwzględnia niedostatyeczność przechyłki względnie nadmiar przechyłki $0,2 \mathrm{~m}$.

Dla pełnej analizy skrajni zestawu należy uwzględnić w omawianym przypadku (pojazdu specjalnego - bimodalnego) wpływ luzu na ślizgach bocznych. Należy tego dokonać $\mathrm{z}$ uwagi na to, że rozważany pojazd możemy potraktować jako wagon towarowy dwuosiowy. W kodeksie [4] nie ma bowiem odpowiednika bardziej zbliżonego do rozpatrywanego pojazdu. Dlatego rozważyć należ przypadek wagonów towarowych, których luz ślizgów jest większy niż $5 \mathrm{~mm}$. W tym przypadku trzeba uwzględnić dodatkowe pochylenie $\alpha$ pudła pojazdu, które opisujemy zależnością:

$$
\alpha=\operatorname{artg} \frac{J-0,005}{b_{G}}
$$

To dodatkowe pochylenie $\alpha$ wpływa na odkształcenie usprężynowania. Jeżeli pomnożymy $\alpha$ przez współczynnik pochylania s uzyskamy pochylenie pudła. Całkowite dodatkowe pochylenie wynosi: $\alpha(1+s)$

Całkowite wyrażenie z, które uwzględnia luz ślizgów większy niż $5 \mathrm{~mm}$ jest następujące:

$$
\begin{aligned}
& z=\left[\frac{s}{30}+\operatorname{tg}\left[\eta_{0}+\left(\operatorname{arctg} \frac{J-0,005>0}{b_{G}}\right)(1+s)-1^{\circ}\right]_{>0}\right] \\
& \left|h-h_{c}\right|+\left[\frac{s}{10}\left|h-h_{c}\right|-0,04[h-0,5]_{>0}\right]_{>0}
\end{aligned}
$$

Zwężenia quasistatyczne, jak pokazuje powyższa zależność, są uzależnione od wielu czynników. Poszczególne jego elementy są również parametrami zależnymi od różnych składowych mających wpływ na jego wartość.

- $\quad$ s - współczynnik pochylenia, który zależny jest od masy pojazdu Qr", sztywności usprężynowania $\mathrm{c}_{\mathrm{k}}$, wysokości środka ciężkości $\mathrm{h}_{0}$ oraz wysokości bieguna przechylania $h_{c}$. Wszystkie te wartości podlegają określonym odchyłkom, tolerancją lub są przyjmowane ryczałtowo. Można więc przyjąć, że odpowiednie przyjęcie pól tolerancji, uwzględniające najnowsze metody pomiarowe i obróbkowe $\left(c_{k}\right)$, obliczenia rzeczywistych parametrów zamiast przyjmowania wartości ryczałtowych $\left(\mathrm{h}_{\mathrm{c}}, \mathrm{h}_{0}\right)$, oraz przyjęcia założonych (narzuconych) wartości ( $\mathrm{Q}_{\mathrm{r}}$ ”) zamiast przypadkowych określić wartości ściśle dla rozpatrywanego przypadku,

- $\eta_{0}$ - kąt niesymetrii wagonu, przyjmowany zazwyczaj jako ryczałtowy $1^{\circ}$. Wartość jego w sposób dokładny można określić obliczając:

- $\eta_{01}$ - kąt niesymetrii wynikający $\mathrm{z}$ wyczerpania luzów na ślizgach bocznych sprężystych,

- $\eta_{02}$ - kąt niesymetrii wynikający $\mathrm{z}$ przesunięcia ładunku,

- $\eta_{03}-$ kąt niesymetrii wynikający z tolerancji wykonawczej.

Dokładne określenie wartości powyższych parametrów pozwoli na wyznaczenie rzeczywistego „zapotrzebowania" na skrajnię, a stosując nowoczesne metody pomiaru luzów czy zabezpieczania ładunków będzie można określić, czy pochylenie przyjmowane 
$1^{\circ}$ jest uzasadnione.

- J - maksymalny luz pionowy na ślizgach bocznych - wartość ta przyjmowana jest zazwyczaj z dokumentacji konstrukcyjnej. Analiza najnowszych metod regulacji ślizgów, wpływ innych urządzeń na pracę ślizgów jak tłumiki cierne, powoduje również dokładną ocenę tego parametru.

- $\mathrm{h}_{\mathrm{c}}$ - wysokość środka obrotu masy

Dodatkowo dla wysokości pojazdu powyżej $h \geq 3250 \mathrm{~mm}$, określa się wartości tzw. dodatkowych przesunięć. Wartości tych przesunięć określa się dla pojazdu nowego (bez zużycia), zdolnego do jazdy, oraz przyjmuje się, że pojazd jest w stanie próżnym. Poruszający się pojazd zbliża się do skrajni pod działaniem:

- sił pionowych ku górze,

- składowej pionowej pochylenia quasistatycznego,

- przesunięć poprzecznych, do zarysu odniesienia.

W związku z tym należy zmniejszyć wymiary wysokości zarysu odniesienia o wartość $\xi$, którą należy obliczyć (o ile jak podaje karta będzie to możliwe), albo przyjąć jako wartość ryczałtową $15 \mathrm{~mm}$ przypadającą na stopień usprężynowania.

Wartość obniżenia skrajni przy nadmiarze lub niedostateczności przechyłki określa wzór:

$$
\Delta \mathrm{V}(\mathrm{h})=\xi\left\{\frac{\left[\frac{1}{2} \mathrm{LCR}(\mathrm{h})-\mathrm{E}_{\text {ituba }}\right]}{30}\right\}
$$

gdzie:

$\frac{1}{2} L C R(h)^{-}$połowa szerokości zarysu odniesienia,

$\mathrm{E}_{\mathrm{i}}$ lub $\mathrm{E}_{\mathrm{a}}-$ zwężenia $\mathrm{w}$ kierunku poprzecznym,

s-współczynnik pochylenia pojazdu,

$\xi$ - pionowe wychylenie pojazdu w górę.

Parametry $E_{i}, E_{a}, s$ oraz ich wpływ na wymiary przestrzeni ładunkowej został już omówiony, a zarys odniesieni LCR(h) jest wartością stałą. $\xi$ - pionowe wychylenie pojazdu $\mathrm{w}$ górę można określić poprzez obliczenie lub przyjmując wartość normatywną. Do tej pory $\mathrm{w}$ obliczeniach skrajni pojazdu bimodalnego przyjmowano wartości zryczałtowane. Istotne więc wydaje się sprawdzenie rzeczywistych wartości pionowych wychyleń pojazdu.

Wszystkie parametry, które dotyczą przesunięć quasistatycznych można w zasadniczy sposób ograniczyć za pomocą nowoczesnych metod, lub za pomocą poczynienia odpowiednich założeń. Założenia te dotyczyć mogą np. ładunku, jego gabarytów, masy itp.

\subsection{Człony szczególne}

Są to człony pozwalające na zmodyfikowanie zależności na zwężenia (określonych w 505-1 p. 7.2) dla oddalonych części czopów skrętowych pojazdów z bardzo dużym rozstawem zestawów kołowych i wysięgiem, które ograniczają zapotrzebowanie przestrzenne w tukach toru między $250 \mathrm{~m}$ i $150 \mathrm{~m}$, określone jako $\mathrm{x}_{\mathrm{i}} \mathrm{i} \mathrm{x}_{\mathrm{a}}$.

Elementy te nie będą miały zastosowania w analizie, gdyż stosuje się je tylko dla:

$\mathrm{x}_{\mathrm{i}}$ - uwzględnia się tylko wtedy gdy we wzorach $\frac{\mathrm{a}^{2}+\mathrm{p}^{2}}{4}>100$, a więc przy wartości zbliżonej do $20 \mathrm{~m}$ dla a. Wymiar ten nie ma zastosowania $\mathrm{w}$ analizie $\mathrm{z}$ uwagi na określoną długość naczepy samochodowej

$\mathrm{x}_{\mathrm{a}}-$ uwzględnia się tylko wtedy gdy $\mathrm{an}_{\mathrm{a}}+\mathrm{n}_{\mathrm{a}}^{2}-\frac{\mathrm{p}^{2}}{4}>120$, a więc jest to przypadek wyjątkowy, również nie mający zastosowania w analizie.

\subsection{Wysięg dodatkowy $S_{0}$}

Wartości wysięgu dodatkowego określane są dla trzech typów pojazdów:

- wszystkie pojazdy trakcyjne lub wagony,

- pojazdy trakcyjne, wagony z pojedynczymi zestawami kołowymi, osobno rozważanymi wózkami jak i związanymi z nimi częściami konstrukcyjnymi,

- wagony z wózkami lub wagony porównywalne.

Wartości te są stałe i stabelaryzowane. Ich wartości określono na podstawie przyjęcia wartości parametrów toru (szerokość toru), które przyjęto dla toru prostego $1,435 \mathrm{~m}$, oraz $1465 \mathrm{~m}$ na luku $250 \mathrm{~m}$.

Parametr ten należy rozpatrzyć z uwagi na:

- wykonawcze odchyłki toru,

- eksploatacyjne parametry toru - zużycie,

Dodatkowo można rozpatrzyć wyznaczenie torów, które będą spełniać określone parametry, oraz prawdopodobieństwo wystapienia danej odchyłki dla danego toru, o czym informuje literatura. Odpowiednie parametry trasy dotyczyć może np. wyznaczenia szlaków o określonych łukach.

\section{Podsumowanie}

Poszukiwanie optymalnych wymiarów systemu bimodalnego na tle skrajni pozwoli na wykorzystanie dostępnej przestrzeni, oraz pozwoli na sprecyzowanie informacji dla możliwych uczestników systemu transportu bimodalnego. Wykorzystanie wszystkich możliwości powiększenia przestrzeni ładunkowej pozwoli zainteresować przewoźników, spedytorów itp. 
Dalsze etapy prac badawczych mają wykazać:

- jaki wpływ może mieć wykorzystanie dostępnych środków konstrukcyjnych taboru, stanu technicznego torów, przepisów itp. na gabaryt przestrzeni ładunkowej naczepy bimodalnej spełniającej warunki kodeksu UIC 505-1,

- porównać otrzymaną przestrzeń ładunkowa $\mathrm{Z}$ przestrzeniami $\mathrm{w}$ istniejących systemach transportowych dla stosowanych zintegrowanych jednostek ładunkowych,

- określenie wymagań jakie powinien spełniać uczestnik systemu bimodalnego aby mógł stać się jego użytkownikiem.

\section{Literatura:}

1. Medwid M., Cichy R.: Systemy transportu intermodalnego na tle wymagań skrajni kolejowej, XVIII Konferencja Naukowa Pojazdy Szynowe - Katowice Ustroń 2008, materiaty konferencyjne.

2. Karta UIC 505-1. Pojazdy kolejowe. Skrajnia pojazdów. Wydanie 9 z 11. $2003 r$.
3. Karta UIC 506. Reguly dotyczace zastosowania skrajni powiększonych GA, GB, GC. Wydanie $z$ 01.01.1987r.

4. Obliczenia skrajni pociagu bimodalnego - archiwum IPS.

5. OR-8126 Obliczenia skrajni pociagu bimodalnego typu BMDo i kodyfikacja dla międzynarodowego transportu kombinowanego. Poznań, czerwiec 1999. OBRPS.

6. OR-8474 Analiza $i$ obliczenia skrajni pociagu bimodalnego typu BMDo i kodyfikacja do ruchu międzynarodowej komunikacji z Wielka Brytaniq. Poznań, czerwiec 2002. IPS , TABOR”

7. OR-8473 Analiza $i$ obliczenia skrajni pociagu bimodalnego typu BMDo dla poszerzonych zarysów odniesienia GA, GB i GC. Poznań, kwiecień 2002. IPS ,TABOR”

8. OR-9302 Sprawozdanie z obliczeń skrajni pociagu bimodalnego. Poznań, marzec 2008. IPS ,, TABOR”.

9. Gqsowski W., Sobaś M.: Nowoczesna skrajnia pojazdów kolejowych. Poznań 2005.

10. Medwid M., Cichy R.: Systemy transportu intermodalnego na tle wymagań skrajni kolejowej, XVIII Konferencja Naukowa Pojazdy Szynowe Katowice Ustroń 2008, materialy konferencyjne. 